\title{
Ecoespiritualidade: religião e a nova gramática espaço-temporal
}

\section{Eco-spirituality: religion and the new space-time grammar}

\author{
Emerson José Sena Silveira* \\ João Paulo Silveira**
}

Resumo: $\mathrm{O}$ artigo discute, teoricamente, a relação entre ecologia e religião na modernidade tardia e questiona se a ecoespiritualidade seria uma nova gramática espaço-temporal. Nosso propósito é compreender algumas das respostas religiosas às interpelaçõos feitas pela crise ambiental. Entendemos que as contingências ecológicas estimulam novas concepçóes e práticas religiosas no tempo e no espaço, e promovem um deslizamento da religião institucionalizada para uma dimensão de espiritualidade. Tendo como método a revisão bibliográfica orientada pelo binômio religião-ecologia, lançamos a hipótese de que ecoespiritualidade, conjugada no plural como religiosidades ecologicamente reimaginadas, procura se contrapor à teleologia do progresso que se move em uma perspectiva espaço-temporal linear, evolucionista e positivista-quantitativa. A ecoespiritualidade traz uma sensibilidade ambiental que aponta para o horizonte holístico da relação entre humanos e não humanos.

Palavras-chave: Ecoespiritualidade. Modernidade tardia. Crise ambiental. Nova gramática espaço-temporal.

Abstract: This paper theoretically discusses the relation between ecology and religion in late modernity and questions whether eco-spirituality would be a new space-time grammar. Our purpose is to understand some of the religious responses to the interpellations raised by the environmental crisis. We understand that ecological contingencies stimulate new religious conceptions and practices in time and space and promote a shift from institutionalized religion to a dimension of spirituality. Methodologically, we apply bibliographical revision guided by the religion-ecology binomial to support the hypothesis that eco-spirituality, conjugated in the plural as ecologically reimagined religiousness, seeks to counteract the teleology of progress that moves in a linear space-time, evolutionist and positivist- quantitative perspective. The eco-spirituality brings environmental sensitivity to the holistic horizon of the relationship between humans and nonhumans.

Keywords: Eco-spirituality. Late modernity. Environmental crises. New space-time grammar.

* Doutor em Ciência da Religião (UFJF). Professor do PPG em Ciência da Religião da UFJF. ORCID: 0000-0002-5407-596X - contato: emerson.pesquisa@gmail.com

** Doutor em Sociologia das Práticas e Representações Sociais (UFG). ORCID: 0000-0003-0158-1735 - contato: jpsilveirahistoria@gmail.com 


\section{Introduçáo}

A questão ambiental interpela a reflexividade e as expressóes religiosas dos seres humanos contemporâneos. Ao longo das últimas décadas, o verde aguçou a sensibilidade e as disposiçôes ideológico-culturais por todo o mundo. Esse movimento contrapóe-se ao espaço-tempo linear, quantitativo-positivista e evolucionista da gramática espaço-temporal que se constituiu junto com os processos que deram origem ao mundo moderno-ocidental (Sloterdijk, 2008). Formou-se um padráo ideológico que afetou as dimensōes da política e da religião (Sloterdijk, 2008). Durante esse período, irrompendo de dentro dos limites da gramática espaço-temporal moderna, emergiram novas sensibilidades e disposiçóes ambientais cruzadas com aspectos místicos e espirituais (Sloterdijk, 2008). Das animaçóes de Hayao Miyazaki ${ }^{1}$ às discussóes sobre o uso de agrotóxicos e à incorporação de práticas terapêuticas integrativas no sistema público de saúde e em algumas estruturas religiosas, como pastorais católicas ou centro espíritas, é possível encontrar ideias, reflexóes críticas e terminologias diversas que constituem uma trama polissêmica, permeada por tendências distintas e conflituosas que problematizam a relação entre a humanidade e a natureza.

Os significantes "sustentabilidade", "preservação", "harmonia", "holismo", "orgânico", "biocêntrico", "biorregional" e o que tomaremos como denso para nossa reflexão, "crise ambiental", são mais familiares; tornaram-se corriqueiros nos debates públicos, nas relações internacionais, nas tecnologias dietéticas, nas casas legislativas, na militância política e na indústria cultural. Seus usos e abusos são sempre acompanhados de representaçóes e expectativas de mundo pertinentes aos diversos nichos culturais, espaços privados e públicos, das tribunas políticas às tribunas religiosas. Em outras palavras, os significantes implicados à questão ambiental são disputados, empunhados, afirmados ou refutados em uma trincheira global e com tramas localizadas e rizomáticas.

A questão ambiental também interpela a religião na contemporaneidade (Nash, 2005). Em virtude disso, propomos discutir neste estudo o que chamamos, a partir de Christopher Partridge (2005), de ecoespiritualidade. Isto é: as imbricaçōes e afinidades entre a busca religiosa e a consciência ambiental moderna. Nosso problema são os sentidos de mundo elaborados pela imaginação religiosa a fim de responderem as carências de orientação provenientes dos dilemas ecológicos contemporâneos. Argumentamos que a ecoespiritualidade é um fenômeno difuso, cheio de religiosidade translúcida e globalmente orientado que procura responder às contingências que caracterizam a sociedade de risco global através do "reencantamento" da relaçáo entre a humanidade e a natureza. Essa resposta pressupóe a sensaçáo de habitar um mundo; suas expectativas apontam para o advento da Era Ecozóica, uma nova era de integração entre a humanidade e a natureza ${ }^{2}$ que contrasta com o que acreditam ser uma era antropocêntrica.

1 O animador e desenhista japonês Hayao Miyazaki é autor, entre outras, das animaçóes Nausicaä do Vale do Vento (1984) e Princesa Mononoke (1997). Ambos possuem narrativas que destacam o embate entre a tecnocracia e a natureza.

2 Segundo pensam os escritores ecoespiritualistas com quem travamos contato, a Era Ecozóica diz respeito a um período futuro em que a dicotomia entre humanidade e natureza inexistiria (Berry; Swimme, 1992). 
Dividimos o texto em quatro momentos. Chamamos a atenção para a "virada verde" experimentada ao longo da segunda metade do século passado. Como tentaremos mostrar, a virada verde também interpelou a imaginação religiosa, criando condições para o surgimento da ecoespiritualidade. No segundo momento, discutiremos o horizonte de expectativas da ecoespiritualidade. Cotejaremos as publicaçóes de autores ecoespiritualistas a fim de elencar alguns dos aspectos mais marcantes da narrativa religiosa. $\mathrm{Na}$ terceira seção, trataremos de aspectos ético-religiosos face ao contexto global. Por fim, trataremos da ecoespiritualidade. Antes de seguirmos, é importante mencionar que as relações entre as religiōes e a natureza são ambíguas, complexas, marcadas pela história e pelos contextos, por um lado, e articuladas a grandes eixos axiológicos, por outro. As hierofanias produziram uma topografia sagrada que representou desertos, florestas, rios e montanhas como lugares privilegiados para o acesso ao numinoso (Eliade, 2008). Animais e plantas também se coloriram de variadas semânticas, de cores religiosas a cores sencientes, ora servindo como sinais da presença superior, ora como manifestaçóes evolutivas e comportamentais.

Amiúde, a natureza foi representada como uma força terrível e ameaçadora na medida em que seus fenômenos poderiam expressar a fúria de uma divindade punidora. Ao mesmo tempo, o mundo ocidental, em sua longa existência e períodos históricos, conferiu à natureza a noção de exuberância, fertilidade e beleza que foram associados aos simbolismos de um cosmo divino ou a benevolência divina. São essas as duas sensibilidades mais comuns em relaçáo ao que representa a natureza, vista desde o horizonte religioso e cultural. A ambiguidade é ainda mais marcante quando pensamos no lugar que o corpo - aquilo que por excelência nos lembra que nós também somos parte da natureza, portanto perecíveis e repletos de pulsóes - ocupa na vida religiosa: o corpo da prece, o corpo da penitência, o corpo do êxtase, do pecado, do martírio, da peregrinação etc. É impossível considerarmos a história das religiōes em sua totalidade sem levar em consideração a relação entre religião e natureza.

\section{A virada verde e a religiosidade: uma nova gramática espaço-temporal?}

O cuidado com o meio-ambiente é uma questão moderna que ganhou relevância planetária ao longo das últimas décadas. A “sociedade de risco", expressão cunhada por Ulrich Beck (2010) na década de 1980, descreve o estágio da modernidade em que somos confrontados pelos perigosos efeitos colaterais oriundos da industrialização, da tecnologia e do consumo em escala planetária. Essa preocupação plasmou o significante "crise ambiental" para se referir ao esgotamento dos recursos naturais, à extinção de várias espécies de seres vivos, ao risco do desaparecimento de biomas e às outras calamidades que ameaçam a natureza e a sobrevivência da espécie humana, identificada como a principal responsável pela crise que ameaça a vida em sua totalidade. Por sua vez, as tragédias e os crimes ambientais, como são os casos de Fukushima, no Japão, 
em $2011^{3}$, e de Mariana, no Brasil, em 2015, ou ainda as crises de gestão hídricas ${ }^{5}$ enfrentadas por vários cantos do planeta, inclusive em nosso país, deixam claro que os riscos não são geograficamente pontuais ou acidentes de percurso, mas desdobramentos de grandes empreendimentos humanos cuja ganância, desperdício, inépcia, impunidade e desrespeito ameaçam a vida dos rios, dos mares, das florestas e a vida humana. Tudo isso interpela a reflexividade contemporânea e a maneira de viver e pensar a religiáo.

Apesar de encontrarmos as origens do pensamento ambientalista na passagem no século XVIII, contexto da industrialização, da ampliação da malha urbana e do desenvolvimento do pensamento científico ocidental, a sensação de risco ambiental ganhou relevo político ao longo da segunda metade do século passado através da ampliaçáo da consciência a respeito do impacto da ação humana sobre os ecossistemas e sobre os recursos naturais. O desdobramento dessa realidade sobre a sensibilidade contemporânea produziu a "cultura ambientalista" capaz de orientar perspectivas políticas, arranjos sociais e iniciativas terapêuticas em relação à natureza, amiúde representada como refrigério dos tormentos humanos. A cultura ambientalista atravessa a imaginação religiosa dos sujeitos e favorece o florescimento da ecoespiritualidade. As críticas antropológicas ao entendimento tradicional da natureza - "um conjunto de condiçóes objetivas que existem independente e anterior às criaturas que vêm habitá-lo, e ao qual devem forçosamente se adaptar" (Ingold, 2015, p. 129) - ganham espaço e reconfiguram ideias (ecoespiritualidade e sensibilidade dos humanos e náo humanos).

A emergência da ecoespiritualidade é contígua ao desenvolvimento da militância ambientalista. Para Isabel Carvalho e Carlos Alberto Steil (2008), existem horizontes imaginativos comuns entre ecologia e espiritualidade. Gottlieb (2010) argumenta que a linha que separa suas percepçóes e iniciativas é de difícil precisão quando procuramos algumas de suas raízes. Suas afinidades se devem ao compartilhamento do mesmo espírito crítico em relação aos impactos ambientais do progresso, mas também às sensibilidades contemporâneas que lamentam a anomia urbana e o automatismo das relaçóes sociais, ao mesmo tempo em que desejam uma vida autêntica. Ela se torna mais densa em virtude do compartilhamento, por alguns grupos, da "imagem de mundo ecocêntrica" 6 que se apresenta como alternativa aos valores da sociedade de consumo, ao individualismo e ao utilitarismo que constituem o "espírito do capitalismo" hodierno7.

3 O incidente de Fukushima diz respeito ao desastre nuclear provocado pelo tsunami que atingiu o Japão em 2011. O tsunami abalou as estruturas da Central Nuclear de Fukushima I, o que levou à liberação de materiais radioativos.

4 O incidente de Mariana, em Minas Gerais, diz respeito ao rompimento da barragem do Fundão, que continha os rejeitos da mineradora Samarco, pertencente ao Grupo Vale e à anglo-australiana BHP, no dia 5 de novembro de 2015. Segundo matéria da Folha de Sáo Paulo (08-12-2015), cerca de 40 bilhôes de litros de rejeitos foram lançados sobre o Rio Doce, destruindo povoados e sendo lançados no Oceano Atlântico.

5 Optamos por "crise de gestão hídrica" ao invés de simplesmente "crise hídrica" por entendemos que a questão da água não diz respeito apenas à falta de chuva ou às particularidades hidrográficas, mas sobretudo ao uso pouco racional dos recursos hídricos e à falta de fiscalização quanto ao mau uso.

6 Seguindo a pegada de Pepper (2003), compreendemos que a imagem de mundo ecocêntrica é integradora: a humanidade é parte da natureza. Para além da obviedade biológica dessa ideia, a integração é substantiva: reconhecer-se como unidade é se sentir irmanado com a natureza e habitante de uma "casa comum".

7 Gottlieb (2010) afirma que o pensamento ambientalista é possuidor de uma propensão espiritual inigualável se comparado com outras correntes do pensamento crítico. "Walden”, de Henry David Thoreau (1817-1862), um dos textos precursores ("ambientalistas"), é uma crítica à sociedade urbana e capitalista. 
Episódios na segunda metade do século passado - em especial à crise da narrativa moderna do progresso, a contracultura e o pensamento ambientalista -favoreceram a efervescência ecoespiritual (Pepper, 2003). Todos eles, de certa forma, convergem na crítica ao modo de vida ocidental em sua totalidade. A economia capitalista, o patriarcalismo assentado em valores religiosos e determinadas nuances do pensamento ocidental, em especial aquelas que são associadas ao antropocentrismo e ao pragmatismo, foram problematizados por vários grupos/tendências políticas e por intelectuais comprometidas com ideias de liberdade.

O sentimento de que a natureza estava ameaçada pela humanidade alimentava a disposição política dos indivíduos, fazendo nascer a militância ambiental como a conhecemos hoje. Nesse contexto de crítica e de expectativas de um novo mundo, tradiçóes religiosas diversas foram escrutinadas e reimaginadas, e muitas delas são representadas como alternativas ao tipo de cristianismo associado aos valores dominantes e ao antropocentrismo. As disposições religiosas orientalistas, esotéricas e espiritualistas que eram fermentadas pela imaginação religiosa ocidental desde o século XIX imbricaram com outras disposiçóes políticas e ambientais de nosso tempo (Partridge, 2005). As mundivisões e práticas budistas, hinduístas ${ }^{8}$, xamânicas, pagãs, indígenas e cristãs foram ecologicamente reimaginadas a fim de uma nova forma de relacionamento com a natureza $^{9}$ (Gottlieb, 2010) ${ }^{10}$. Como argumentaremos ainda, a pluralizaçáo dos itinerários religiosos na modernidade teve um papel importante nesse processo na medida em que ela implicou a destradicionalizaçáo da paisagem religiosa e o relativo enfraquecimento da religião do tipo institucional.

Inscrito nesse quadro de contestação e expectativa, a Hipótese Gaia tornou-se uma referência para o entretecimento da narrativa ecoespiritual (Partridge, 2005). Construída nos anos de 1970 por James Lovelock e Lynn Margulis, a hipótese controversa no meio científico definia o planeta como um superorganismo que engloba o mundo físico, gasoso e os oceanos, mas também os seres vivos que constituem uma totalidade interdependente. Segundo Lovelock (2000), um dos idealizadores dessa ideia, ocupamos o lugar de consciência de Gaia, seu coração e sua mente, o que não quer dizer que sejamos gerentes ou proprietários com total direito sobre o planeta e sobre a vida que existe nele.

Segundo Partridge (2005), a Hipótese Gaia foi incluída pelos circuitos esotéricos, pagãos e de espiritualidades Nova Era que encontram nela uma expressão de seu entusiasmo pelo contato profundo com a natureza, o que não incomodou Lovelock, até hoje um ícone para aqueles que pensam a dimensão espiritual da relação com o meio ambiente. A ideia da Mãe Natureza nutridora se tornou parte fundamental do vocabulário ambientalista e ecoespiritual. A ideação religiosa ao redor de Mãe Natureza é

8 Para além do exemplo cristão, sobretudo em virtude da Encíclica Papal Laudato Si, constata-se no hinduísmo ponderaçóes sobre a doutrina do Karma que atentam para o cuidado com a natureza como forma de não violência contra o próximo, incluindo todos os seres sencientes (Dwivedi, 2006).

9 No budismo, é possível verificar a prática meditativa guiada conhecida como "Meditação da Tangerina”, que sugere a atenção plena durante a refeição com vistas à desaceleração e à harmonia com o mundo natural Thich Nhat Hanh propaga este tipo de meditação.

10 Outras práticas e iniciativas diárias, entre elas o vegetarianismo e o não consumismo, alinham o ideal do bodhisattva aos valores ecologicamente orientados (Kaza, 2010). 
localizada, isto é, traduzida, a partir de outros avatares e referências religiosas regionais, como é o caso da deusa Pachamama ${ }^{11}$. Os cuidados com a natureza são associados à vida ou aos atributos de personagens religiosos diversos, como São Francisco de Assis, no cristianismo, e Kuan Yin, no budismo ${ }^{12}$.

Relevante para o florescimento da ecoespiritualidade foi a "ecologia profunda" (deep ecology, em inglês), manancial filosófico desenvolvido pelo norueguês Arne Naes na década de 1970, que se tornou peça fundamental para a imagem de mundo ecocêntrica (Pepper, 2003). As reflexôes de Naes apontavam para o valor intrínseco dos seres - incluso rios, oceanos etc. - independentemente de sua utilidade para propósitos humanos. Há, nesse aspecto, intensos cruzamentos e mudanças que apontam para novas possibilidades. Tome-se como um exemplo a crescente visibilidade, em fóruns mundiais sobre políticas de conservaçáo da natureza, os sítios naturais sagrados (SNS). Reconhecidos em muitos lugares no mundo, os SNS's expressam os valores espirituais e a visão de sacralidade da natureza de grupos sociais, muitos deles marginalizados e perseguidos, sendo considerados elos entre a diversidade biológica e cultural (FernandesPinto, 2017).

A aceitação do valor inerente desses seres rejeitava o entendimento de que a natureza é um objeto a ser manuseado com o propósito de atender interesses humanos. Ao apontar a relação entre o indivíduo e a natureza, Naes (1995, p. 80, tradução nossa), descreve de maneira quase mística a "autorrealizaçáo do eu" a partir de uma consciência ecológica que conduz o sujeito à identificação com toda vida natural.

Eu não uso essa expressão [autorrealização] em um sentido estreito, do tipo individualista. Como conceberam determinadas tradiçóes orientais a respeito do atman, eu quero expandir seu sentido baseado na distinçáo entre um eu profundamente compreensivo daquela concepção estreita do eu egoísta [...] Visto sistematicamente e não individualmente, ampliar a autorrealização significa maximizar a manifestação de toda a vida [...] Isso conduz à hipótese acerca do inescapável crescimento da identificação com outros seres como ampliaçáo da nossa autorrealização. Como resultado, cada vez mais nos vemos em outros seres e eles se veem em nós. [...] o eu se dilata e se aprofunda enquanto processo natural da realização de suas potencialidades nos outros.

O pensamento crítico do pós-colonialismo e o feminismo também tiveram influência no desenvolvimento da ecoespiritualidade na medida em que suas críticas colocaram em xeque os arranjos sociais ocidentais e a autoevidência da teleologia Iluminista. A denúncia do patriarcalismo e a crítica da razão colonial europeia - que procurava erodir outras mundivisóes e saberes cridos como tradicionais e populares - estimularam o

11 Pachamama é o nome de uma deidade telúrica andina quem em nossos dias aparece identificada como a Mãe Terra ou a Mãe de Todos. Seu alcance simbólico inclui a defesa ambiental e os direitos dos animais (Zaffaroni, 2011). A deusa é associada com a fertilidade e o sagrado feminino (Eliade, 2008). Acreditamos que sua imagem, enquanto símbolo ecológico latino, evoca os saberes dos povos tradicionais.

12 Kuan Yin é o nome chinês de Avalokiteśvara, o Bodhisattva da Compaixão cultuado no Sudeste Asiático e, de modo geral, na tradição Mahayana. $\mathrm{Na}$ Índia, Avalokiteśvara é um personagem religioso do sexo masculino. Na China e em outros países do Sudeste Asiático, o Bodhisattva é do gênero feminino. Sua figura está associada à Karuna, o princípio da compaixão (Irons, 2008). Stephanie Kaza (1993) sugere que os atributos da compaixão de Kuan Yin, que ela inclusive associa ao feminismo, são fontes inspiradoras do sagrado feminino, representado por algumas escritoras ecofeministas como o oposto do princípio masculino responsável pela depredação e submissão da natureza (Hobgood-Oster, 2005). 
interesse por outras narrativas que concebiam o sagrado para além dos limites de uma "divindade masculina" e dos imperativos civilizatórios europeus.

As críticas pós-coloniais e feministas açularam o fascínio pela diversidade social, cultural e religiosa, uma disposição que incidiu sobre a representação da natureza. Grosso modo, os pós-colonialismos e o feminismo abalaram de formas distintas a autoevidência da narrativa eurocêntrica. Esse processo criou condiçóes para o contato mais denso e auspicioso com outras formas de existir e estar no mundo. O ecofeminismo, que emergiu durante a década de 1970 - o termo foi cunhado pela feminista francesa Françoise d'Eaubonne - autora de Le Féminisme ou la Mort, publicado em 1974 - problematizou as questóes ambientais a partir da crítica ao patriarcado e suas cosmologias religiosas dualistas (esforços de sujeição das mulheres e pela destruição da natureza). Essa postura estimulou o interesse pelas referências mitológicas femininas e pelo lugar das mulheres nas religiōes (emancipação das mulheres e questão ambiental) (Hobgood-Oster, 2005; Eaton, 2017). Nesse âmbito, expressóes como o Sumak Kawsay, o "bem-viver" em língua quéchua, e o conceito africano Ubuntu, traduzido por "eu sou porque nós somos", se tornaram significantes que evocam outro tipo de sociabilidade distinta da de um capitalismo selvagem e predatório. O sistema capitalista, em suas facetas mais tecnológicas e contemporâneas, aposta em tecnologias, mercados e formas de consumo ditas "verdes", ou seja, que incorporam as questóes postas pelos movimentos ambientalistas e sociais que defendem novas posturas de produção e consumo.

Coextensivamente, elas evocam outra maneira de se relacionar com a natureza a partir de exemplos oriundos dos povos ancestrais ${ }^{13}$. Por sua vez, a crítica à religiáo patriarcal estimulou a representação do sagrado a partir de traços femininos, o que deu origem às teologias ecofeministas e ao movimento de culto às divindades femininas amiúde relacionadas às forças criativas da natureza e praticada por indivíduos com pendor ambientalista. Destaca-se o "Movimento da Deusa" - Goddesses movement, em inglês -, que, grosso modo, procura enfatizar a relaçáo com o sagrado feminino como uma disposição religiosa e ecológica que contrasta com o monoteísmo tradicional.

O "renascimento" da deusa no contexto religioso contemporâneo do ocidente é uma inovaçáo religiosa deliberada inscrita no contexto de rebeliáo contra a forma tradicional da religiáo, o monoteísmo masculino. [...] Muitos adoradores contemporâneos da deusa, independentemente de serem feministas ou não, pagãos ou não-pagãos, alegam que suas religióes são verdadeiramente mais ecológicas do que a contraparte tradicional em virtude das ideias e práticas comuns às religióes da deusa. Eles alegam que a teologia da imanência, cuja divindade é vista como imersa na natureza ao invés de separada dela, adota a preocupaçáo com a Terra. Eles apontam suas estórias sagradas que celebram os ritmos sazonais da natureza e os rituais direcionadas ao sol $\mathrm{e}$ às estaçôes. [...] Muitos adoradores da deusa assim como vários judeus e cristãos favoráveis à imagem feminina de sua divindade também são ambientalistas (Gross, 2005, p. 705, tradução nossa).

13 Sumak Kawsay e Ubuntu são direcionamentos éticos que falam das possibilidades de ser e estar no mundo. Segundo Eugênio Raúl Zaffaroni (2011), uma obra que se debruça sobre os direitos dos animais, o Sumak Kawsay designa o paradigma indígena da convivência harmoniosa entre humanos e a natureza. $\mathrm{O}$ conceito ainda é atravessado pela ênfase na vida comunitária e pela crítica ao modo de vida capitalista. Ubuntu sugere o entendimento de que "ser humano significa ser por meio de outros", conforme o filósofo e psicólogo sul-africano Dirk Louw (Sbardelotto, 2010). 
A despeito das críticas que associam o cristianismo ao antropocentrismo e à crise ambiental, é possível considerar seu lugar no desenvolvimento da ecoespiritualidade ${ }^{14}$. Para além das ambiguidades no que toca ao cuidado com a natureza, lideranças e leigos cristãos se posicionaram sobre a questão ambiental, associada às questóes atinentes à justiça social, como ainda discutiremos.

A declaração de Bartolomeu I, patriarca de Constantinopla, em 1997, ilustra o interesse de grupos/setores cristãos em responder à cultura ambientalista:

Cometer um crime contra o mundo natural é um pecado [...] provocar a extinção de uma espécie e destruir a diversidade biológica da criação divina [...] degradar a integridade da Terra a partir de mudanças de seu clima, despojar a Terra de suas florestas naturais ou destruir seus pântanos [...] contaminar a água da Terra, seu solo, seu ar e sua vida com substâncias venenosas - tudo isso são pecados! (Bartolomeu I apud Gottlieb, 2010, p. 13, tradução nossa).

Personagens, grupos e instituiçóes religiosas aderiram à ecoespiritualidade a partir de seus lugares distintos e de suas distintas configuraçóes religiosas. Eventos, fóruns, congressos e pronunciamentos religiosos ${ }^{15}$ assumiram o cuidado com o meio-ambiente como parte fundamental de seus preceitos éticos. A diversidade desses grupos nos impede de levar adiante qualquer esforço de descrição densa em um estudo como este. Basta-nos ter em mente que hoje é possível encontrar a sensibilidade ecoespiritualista no monoteísmo, nas religióes de matriz hinduísta, confucionista, taoísta e budista, nas religiōes africanas e outros grupos inspirados em tradições xamânicas e pré-cristâs, além, é claro, da diversidade que constitui a Nova Era e os novos movimentos religiosos. Autores, estudiosos, líderes religiosos como Thomas Berry, Leonardo Boff, Thich Nhat Hanh, Vandana Shiva, André Trigueiro, Masanobu Taniguchi, Kaka Wera, Dalai Lama e, mais recente, o Papa Francisco, são alguns dos inúmeros expoentes de uma sensibilidade que atravessa grupos, instituições e sistemas distintos e marcam a fase da "virada verde" das religiosidades.

\section{Horizonte de expectativa: a Era Ecozóica}

De maneira geral, as religióes éticas produzem narrativas a respeito de um outro mundo ou de outra realidade passível de ser alcançada quando determinados procedimentos

14 O ensaio de Lynn White Jr. intitulado The Historical Roots of Our Ecology Crises, publicado em 1967, portanto na aurora da ecoespiritualidade, endereçava ao cristianismo a pecha de religião antropocêntrica. John Grim e Mary Evelyn Tucker (2014) entendem que historicamente a relação entre as religióes abraâmicas, especialmente o cristianismo, e a natureza foi ambígua. A ambiguidade se deve, de maneira geral, às interpretações que definem a criação divina como boa e bela e aquelas que afirma que a natureza caiu junto com a humanidade em virtude do pecado original, uma observação que também é feita por Keith Thomas (2010). James A Nash (2005), em um dos verbetes dedicado ao Cristianismo na obra The Encyclopedia of Religion and Nature, chama a atenção para o fato de que o cristianismo, assim como qualquer religião longeva e geograficamente abrangente, não é um monólito.

15 Marcial Maçaneiro (2011) registra que desde a década de 1980 acontecem fóruns e congressos religiosos que tematizam a relação entre religiáo e ecologia. Dentre eles, o autor destacou o Fórum Global de Líderes Espirituais e Governamentais, cuja primeira edição foi em 1988. Além disso, algumas sessóes do Parlamento da Religiōes Mundiais trataram de questóes ambientais nas ediçóes que aconteceram em Chicago (1993), Barcelona (1994) e Melbourne (2009). 
éticos e espirituais são observados. A realidade vindoura é o desdobramento de uma teleologia que culmina no surgimento do tempo da realizaçáo, da inteireza, da justiça e da plenitude. $\mathrm{Na}$ ecoespiritualidade, esse horizonte de expectativa se realiza com o advento da Era Ecozóica, expressáo cunhada por Thomas Berry e Brian Swimme (1992) para distinguir o advento de uma nova era de relaçóes com o meio- ambiente ${ }^{16}$. A Era Ecozóica expressa a nova gramática espaço-temporal que as ecoespiritualidades divisam. Nela, tempo e espaço são concebidos de forma distinta em relaçáo à linearidade e à ênfase ao quantitativo, associadas à modernidade, isto é, o tempo e o espaço são desmecanizados. A humanidade se relacionaria de forma fraterna com as outras espécies ao invés de submetê-las a partir de interesses estritamente econômicos.

No Ecozóico, predomina o senso de unidade entre humanidade e natureza. Esse novo mundo florescerá, segundo acreditam, a partir da superação do que Leonardo Boff e Mark Hathaway (2012) chamam de "Cosmologia da Dominaçáo", o ethos moderno cientificizante e capitalista responsável por mecanizar as representaçóes da natureza.

A ecoespiritualidade, ao enfatizar os traços constituintes de sua cosmologia, faz o uso do contraste: ciência e capitalismo, associados à modernidade e ao antropocentrismo, sáo apontados como responsáveis pela confecção de visóes de mundo que esvaziam a natureza de propósito. Esse entendimento expressa o descontentamento com a razão instrumental moderna enquanto responsável pelo "desencantamento" da natureza.

A síntese cartesiano-newtoniana gradualmente ganhou dominância; primeiro no mundo das ciências e depois na sociedade em geral. Com isso, a alma e o espírito foram efetivamente extirpados do mundo. O cosmo, que no passado foi uma catedral de luz, tornou-se um ordenado, mas enfadonho, maquinário. A terra passou de grande viva para matéria morta, tornou-se um mero armazém de matérias-primas esperando pela exploração humana (Boff; Hathaway, 2012, p. 221)

A observação crítica dos autores é endereçada ao pensamento científico moderno enquanto forma de conhecimento responsável por tornar a natureza apenas um objeto de manuseio, especialmente no trecho da citação acima, em que lemos que "a alma e o espírito foram efetivamente extirpados do mundo" (Boff; Hathaway, 2012, p. 221). Essa afirmação sugere, enquanto saída ecoespiritual, uma nova consciência a respeito da natureza baseada no encantamento de toda a vida natural e do universo, embora náo se negue a relevância do pensamento científico em sua totalidade, tampouco seu papel na produção de saberes úteis à causa ecológica. Para Boff e Hathaway (2012), o cosmo é possuidor de um propósito intrínseco e plenitude da vida em sua pujante diversidade.

A ecoespiritualidade trata a relaçáo integrativa em termos comunitários: no Ecozóico, seres humanos e toda a natureza são uma comunidade constituída por relaçóes de reciprocidade, em contraste com o individualismo moderno. A integração deveria superar o "sonho tecnológico" do desencantamento e favorecer novas relaçóes marcadas pela mutualidade e pela sensação de habitar uma comunidade de aprimoramento mútuo.

16 Para os autores, os esquemas temporais cunhados no século XIX para organizar a história terrena (i.e., paleozóico, mesozóico, cenozóico) são arranjos "míticos", não deixam de ser empenhos subjetivos para organizar o tempo. O novo arranjo, a Era Ecozóica, será possível com o triunfo sobre o Tecnozóico. 


\begin{abstract}
Nesse momento, desenvolve-se uma mística profunda acerca do mundo natural. Além da compreensão técnica do que está acontecendo e das direçôes nas quais nós precisamos mudar, estamos experimentando os mistérios profundos da existência através dos encantos do mundo ao nosso redor. [...] estamos agora experimentando um momento cujo significado está além do que qualquer um de nós pode imaginar. $\mathrm{O}$ que pode ser dito é que os fundamentos de um novo período histórico, a Era Ecozóica, tem se estabelecido em cada aspecto da atividade humana. A visão mítica assumiu seu lugar. O sonho falacioso de um paraíso tecnológico e industrial está sendo substituído por um sonho viável de aprimoramento mútuo da presença humana no interior de uma sempre renovada e orgânica comunidade terrena (Berry, 1999, p. 200, traduçáo nossa).
\end{abstract}

O "aprimoramento mútuo" sugere um nível de vínculo substancial e místico com o universo cujas as energias e forças constituem o animado e o inanimado. $\mathrm{O}$ aprimoramento para a comunidade humanidade-natureza descreve a dimensão integrativa ou holística que caracteriza a Era Ecozóica. Para o autor, a comunidade náo é apenas aquela de sujeitos humanos, mas a totalidade sagrada que inclui seres vivos e a realidade biofísica de todo o universo (Berry, 1999, p. 49).

A preocupaçáo ético-religiosa com a casa comum possui, como era de se esperar, direcionamentos práticos arranjados a partir do ideal holístico. O combate ao individualismo, ao desperdício e ao consumismo são algumas das faces mais elementares da ética que procura criar as condições para o surgimento do Ecozóico. Elas promovem o ideal de "viver com o essencial" através da redução do excesso de necessidades como meio de experimentar uma vida simples, sustentável, solidária, criativa e sem agressōes aos outros seres vivos (Kumar, 2013). A essas ideias é possível acrescentar a contemplaçáo da natureza, a residência em ecovilas, o cultivo e consumo de alimentos orgânicos, o estabelecimento e da defesa dos direitos dos animais, a adesão aos meios de transporte não poluentes, $\mathrm{o}$ interesse por moradias e fontes de energia alternativas e de baixo impacto etc. ${ }^{17}$ Nenhuma dessas práticas são essencialmente religiosas, é importante dizer, mas aparecem no interior das ecoespiritualidades em virtude da afinidade entre as preocupaçóes ecológicas mais amplas e a busca pelo sentido último da vida que que caracteriza a imaginaçáo religiosa. De maneira geral, elas procuram libertar os seres humanos do automatismo, do egoísmo e da pressa do consumismo capitalista.

Ao estabelecer a "desaceleração" da vida e a adesão ao comunitário e ao regional enquanto dimensões da realização espiritual dos indivíduos, as ecoespiritualidades redefinem a gramática espaço-temporal. A vivência comunitária, a horta orgânica, a permacultura e a bioconstruçáo contrastam com o gigantismo da metrópole e do agronegócio. Igualmente, retiros, caminhadas na natureza, encontros de meditação coletiva, terapias alternativas etc. expressam o viés terapêutico da ecoespiritualidade que procura vias alternativas de cura a partir da experiência da harmonia com as "energias do universo". A realização da Era Ecozóica implica a reimaginação do sagrado a partir de atributos associados ao feminino. Gaia, Pachamama, Kuan Yin e outros avatares

17 Parte desse entendimento foi possível a partir do breve contato com a ONG Flor de Ibêz, em Barra do Garças, Mato Grosso, em outubro de 2017. Naquela pequena comunidade, que recebe visitas principalmente de universitários da regiáo do vale do Araguaia, entre os estados de Goiás e Mato Grosso, tateamos uma realidade orientada pela ética ecoespiritual. Havia preocupação com uma nova relação com a natureza nas atividades diárias (bioconstrução, agroflorestal) e prática alimentar vegana. 
míticos testemunham o interesse por representar o divino a partir desses traços. Apesar da condição essencialista dessas representações, o feminino aparece como antagônico aos antropocentrismos que originaram uma civilização em desarmonia com a natureza (Baptista, 2018). Acolhimento, nutrição, vitalidade, contemplação, sabedoria, empatia etc. são representações do feminino em afinidade com a imagem de mundo ecocêntrica.

O sagrado feminino se faz presente em textos e práticas que constituem a Nova Era, o que não significa sua ausência em tradiçôes mais longevas. Muitas vezes influenciada pelas tendências feministas e ecológicas, é possível encontrar a reverência à Grande Mãe nos espaços terapêuticos e nas redes holísticas frequentadas por buscadores religiosos. Evoca-se o reatamento com o sagrado feminino como meio de restauração de um estado de equilíbrio que teria se perdido ao longo da civilizaçáo patriarcal. O reatamento representa o equilíbrio necessário para superação da crise planetária, como afirma a espiritualista e escritora Mirella Faur (2001, p. 15 e 17):

\begin{abstract}
A Grande Mãe representa a totalidade da criação e a unidade da vida, pois ela é imanente, ela existe e reside em todos os seres e em todo o universo, ela é intrínseca à força da vida, aos ciclos da natureza e aos processos de criação [...] Nesse momento crítico de nosso planeta, ressurge a figura poderosa e amorosa da Grande Mãe para nos ajudar a encontrar os meios para restaurar Sua criação e restabelecer o equilíbrio, a paz e a harmonia individual, global, planetária.
\end{abstract}

O restabelecimento do equilíbrio a que se refere a escritora espiritualista diz respeito à superação de uma realidade ordenada pelo masculino, responsável pela desarmonia e por toda sorte de açóes que foram deletérias para o estabelecimento de uma realidade harmônica. $\mathrm{O}$ antropocentrismo, a partir da perspectiva do sagrado feminino, é intrinsecamente patriarcal. $\mathrm{O}$ feminino é associado à vitalidade, à fertilidade e aos ciclos da natureza, portanto ao aspecto criador da vida. Sua condição imanente destaca não apenas a simples onipresença da Grande Mãe, mas sua natureza comum a todos os seres vivos. O sagrado feminino entrelaça demandas de determinados tipos de feminismos à busca religiosa e à defesa da ecologia. As redes da Nova Era que reverenciam a Grande Mãe equivalem o empoderamento espiritual da mulher às relaçóes harmônicas com a natureza já que esta é a expressão vital da Grande Mãe.

\title{
Biorregionalismo e globalizaçáo
}

Em um trecho da obra do geógrafo brasileiro Milton Santos (2001) a respeito da globalização, é possível ler que as transformações sociais, econômicas, políticas e dos meios de comunicação na contemporaneidade viabilizaram o surgimento da "consciência de ser mundo e de estar no mundo". Nessa condição, a experiência social se constitui através da "dialética da vida nos lugares". Santos aponta para a emergência de sensibilidades e percepçóes globalmente orientadas sem que isso signifique o ingresso automático e irrefletido em uma ordem social homogeneizadora, como comumente se espera quando o assunto é o "mundo global". Antes, parece-nos mais sensato falarmos nos imbricamentos entre local e global, isto é, o glocal (Robertson, 2000). 
A preocupação ecológica com a "casa comum" testemunha a "consciência de estar no mundo" aludida por Santos. A certeza de que habitamos uma realidade planetária e que os impactos de determinadas iniciativas podem ser sentidos globalmente é uma realidade contemporânea impactante na vida de todos os povos e suas religióes (Grim; Tucker, 2014). A questão ambiental nos interpela enquanto habitantes de uma moradia, conflituosa e assimétrica, mas que possui um destino comum. Essa condição exerce um papel importante na constituição de sensibilidades ecológicas éticas de alcance global.

$\mathrm{O}$ imbricamento entre o global e regional define alguns aspectos interessantes da ecoespiritualidade. $\mathrm{O}$ interesse por divindades provenientes de sistemas mitológicos regionais, pelos saberes locais e seus detentores e pela ancestralidade expressam o entendimento de que é na regiáo que se encontra a riqueza cultural capaz de garantir uma vida autêntica face aos imperativos homogeneizadores da narrativa do progresso. Embora exista a consciência de que a ação degradante em um canto do mundo é capaz de provocar desequilíbrio em outros, é no âmbito regional, nas relaçóes comunitárias e nos saberes populares locais que se encontra os meios éticos fundamentais para a emergência da Era Ecozóica. Os arranjos socioeconômicos e culturais locais são representados como vias para um outro tipo de economia solidária que contrasta com o capitalismo e seus dispositivos depredatórios. Sem negar a globalidade das relaçóes e a necessidade de um agir global, isto é, a partir de uma ética global, a ecoespiritualidade evoca saberes e práticas regionais e de povos tradicionais.

A ênfase regional enquanto dimensões sociais e políticas de resistência à ideologia do progresso capitalista deram origem ao biorregionalismo - compreendido como filosofia e forma de ativismo social em favor da descentralização produtiva, da pequena-escala, dos saberes regionais e das relaçóes econômicas e políticas a partir da experiência comunitária. Boff e Hathaway (2010) afirmam que a unidade fundamental do biorregionalismo é a comunidade local, a unidade primária para a tomada de decisóes em âmbitos políticos, econômicos e produtivos. $\mathrm{O}$ entendimento a respeito das experiências regionais na elaboração de uma ética ecológica não implica o desinteresse por unidades sistêmicas nacionais ou globais.

Michal McGinnis (2005) afirma que o biorregionalismo celebra a integração e interdependência entre humanidade e natureza - a floresta local, o rio, animais, a montanha etc. Essas disposiçóes "enraizadoras" favorecem o florescimento de sensibilidades ecoespirituais orientadas pelos valores da simplicidade, da desaceleração e da ancestralidade a que aludimos ${ }^{18}$. No âmbito do trabalho, o biorregionalismo sugere ainda que as atividades produtivas devem ser coletivas, sem divisões de gênero, hierarquias e em contato com a natureza. A visão de mundo biorregional procura enfatizar a diversidade diante da homogeneidade característica da teleologia do progresso, responsável pela erosáo de formas de solidariedade comunitárias e conhecimentos tradicionais. A defesa dos saberes terapêuticos e dos modos de vida dos povos tradicionais enfatiza a

18 McGinnis entende que as ideias que constituem o biorregionalismo não são novidades. Antes dessa palavra fazer parte do léxico político moderno, a vinculação mítica e poética com a regiáo era parte das culturas tradicionais. Compreendemos que o biorregionalismo, em sua nuance religiosa, é uma iniciativa de cosmização ou sacralização do regional. 
diversidade cultural e epistemológica que defendem. A diversidade aparece como via alternativa à homogeneidade eurocêntrica. Procura-se valorizar os raizeiros, os xamãs, as doulas, as benzedeiras etc., enquanto agentes possuidores de saberes e promotores de práticas terapêuticas e de vivência que estão integradas com a natureza.

A questão da escala serve para enfatizar também a oposição ao gigantismo urbano e as práticas do consumo exacerbado e da depredação. $\mathrm{O}$ "pequeno" possui implicações no âmbito psicológico, econômico, organizacional e espiritual, segundo aponta o autor ecoespiritualista Satish Kumar (2013). Influenciado pelo economista Ernest Schumacher (1911-1977), Kumar compreende que o "pequeno é belo" - Small is beautiful é o título da mais popular obra de Schumacher - e que a realização da criatividade humana em tempos de crise exige da humanidade um redimensionamento de suas relaçóes econômicas, produtivas, políticas e espirituais a partir da vida da comunidade local, das relaçôes face a face e da intimidade com a natureza. Uma nova relação com a "terra", entendida em sentido de região onde se procura o enraizamento, conduziria à humanidade a um novo paradigma social em que o solo, a alma e a sociedade se vinculariam e harmonizariam. Esse novo paradigma é a ecotopia Ecozóica.

A ética ecocêntrica plasmada a partir do biorregionalismo e suas variáveis está assentada no entendimento de que a relaçáo integradora com a natureza possui um viés terapêutico. A relação integradora implica harmonia interior e bem-estar, já que dentro e fora são percebidos enquanto instâncias relacionais. A via interior evocada pelas ideias de integração e harmonia é possuidora de notas místicas: "[...] a paisagem interior e a paisagem sustentável exterior estão intrinsecamente conectadas (Kumar, 2013, p. 26, tradução nossa). O cultivo de práticas sustentáveis teria, portanto, desdobramento na qualidade da vida interior dos sujeitos na medida em que ela criaria condiçóes para a sensação de se viver uma vida autêntica, isto é, de acesso ao eu verdadeiro que contrasta com o sujeito autômato vinculado ao capitalismo.

\section{Implicaçóes no âmbito da sociologia das religióes}

A compreensão sociológica da ecoespiritualidade exige que consideremos as condiçóes sociais e culturais que tornam plausível sua existência. Ao assumirmos a ideia de que uma determinada realidade permite o florescimento de expressóes religiosas particulares, explicitamos que compreendemos as narrativas religiosas como entretecimento da reflexividade, das expectativas e dos interesses de seu tempo. A despeito da relação entre religiáo e natureza ser uma realidade que nos parece atemporal - afinal, como conceber uma narrativa religiosa sem ela? -, compreendemos que a ecoespiritualidade é uma disposição religiosa que procura responder às crises de orientação típicas da contemporaneidade, mas também uma iniciativa criadora inscrita em uma época em que a rigidez institucional do âmbito das religióes náo incide com o vigor do passado sobre a imaginação religiosa.

A possibilidade sociológica da ecoespiritualidade enquanto fenômeno religioso está relacionada a duas condiçóes complementares que existem como "estruturas de plausibilidade" (Berger, 2017): de um lado, os poderes solventes da modernidade 
derreteram os monopólios religiosos, a capacidade de coerçáo institucional, o que favoreceu a pluralidade religiosa e a individuação da fé. Por outro lado, esses poderes solventes atingiram também a narrativa do progresso cunhada desde o Iluminismo, o que significa que as certezas alicerçadas na racionalidade não gozam de unanimidade e prestígio. Hervieu-Léger (2008, p.41) sintetiza da seguinte forma:

De um lado, são desqualificadas as grandes explicaçóes religiosas do mundo pelas quais as pessoas do passado encontram sentido global. As instituições religiosas continuam a perder sua capacidade social e cultural de impor e regular as crenças e as práticas. [...] De outro lado, esta mesma modernidade secularizada oferece, geradora que é, a um tempo, de utopia e de opacidade, as condiçôes mais favoráveis à expansão da crença.

O fim dos monopólios de fé implicou a impossibilidade de regulação institucional efetiva dos conteúdos e adesóes religiosas. Essa realidade proporcionou o acesso à pletora religiosa contemporânea, livre de regulaçôes institucionais incontestes, e a individuação da crença. A pluralização das veredas devocionais permitiu o trânsito global de religióes e práticas oriundas das diversas partes do mundo, o que estimulou bricolagens e conflitos de tons distintos. No contexto da ecoespiritualidade, tradiçóes diversas foram reimaginadas a partir dos interesses dos indivíduos sensíveis às questôes ambientais: o Tao, Pachamama, Gaia e Kuan Yin, São Francisco, tornaram-se referências para os sujeitos que procuram significantes afins às suas expectativas ecológicas. A problematizaçáo das expectativas vinculadas à ideologia do progresso favoreceu o desenvolvimento de narrativas alternativas que procuram um novo horizonte social de segurança ontológica. A associação entre capitalismo, consumismo e o racionalismo científico à crise ambiental tem como corolário a expectativa de uma nova consciência capaz de pavimentar o advento da Era Ecozóica. O "eco-encantamento" de que fala Partridge (2005) é a resposta à opacidade produzida pela crise da teleologia moderna. Complementarmente, a relação comunitária com a natureza e entre os sujeitos proposta pelo biorregionalismo expressa o entendimento de que a vida na sociedade urbana moderna produziu anomia e fragilização dos laços humanos.

No que toca aos significados da ecoespiritualidade no interior do campo religioso, o pressuposto construtivista levantado por James Beckford (2008) apresenta algumas possibilidades e desafios reflexivos interessantes. Para esse autor, os comportamentos e disposiçóes compreendidas como religiosas e aquilo que nomeamos por religiáo ou "não religião" são suscetíveis aos processos sociais e à opinião dos agentes envolvidos ou não com práticas religiosas. A leitura desse sociólogo ajuda a pensar a religião no hodierno além do registro institucional, das formas tradicionais e homogeneizantes e do arranjo do tipo "igreja" com o qual estamos acostumados, ao mesmo tempo em que nos desafia a pensar nas definiçóes construídas a respeito do que significa ser ou náo ser religioso. Através dessa lente interpretativa, compreendemos o significado religioso que atravessa o ímpeto ambientalista, mas também os comportamentos corriqueiros de alguns sujeitos que procuram, através da alimentaçáo, do cultivo de hortas, da não agressão aos animais ou do turismo ecológico, os meios para alcançar a autêntica experiência de contato com a natureza e consigo mesmos. Novos escopos oriundos da preocupação ambiental tencionam e transformam o significado da religiáo e da vivência religiosa e, por este motivo, práticas cotidianas como o cuidado com o jardim ou o refúgio em uma 
região erma assumem expressam algo próximo aquilo que Thomas Luckmann (2014) nomeou como "religiáo invisível", uma religiosidade de contornos pouco precisos (de pouca identificação entre religião e igreja).

Muito embora a religião interiorizada não seja uma "novidade" histórica, a via ecoespiritual é associada à interiorização e isso se deve ao entendimento de que a transformaçáo espiritual deve acontecer primeiramente no âmbito da consciência, como compreendem Cristiana Carvalho e Carlos Steil (2008) ao discutirem a relação entre ecologia as religióes do eu verdadeiro (self-religion). Para muitos, a experiência com a natureza náo é um passatempo, mas também não é uma prática religiosa, já que este significante pode ser atravessado pelo seu registro institucional e por perspectivas ideológicas que não lhes são muito simpáticas (i.e., prisão, alienação, obscurantismo, etc.). Parece-nos que as práticas da ecoespiritualidade, como retiros, meditaçóes ao ar livre e outros são interpretados como um itinerário espiritual de autoconhecimento que não tem necessária e exclusivamente relação com a religião em sua forma institucional tradicional; filosofia de vida ou espiritualidade aparecem como significantes reflexivos desse tipo e vivência religiosa. Embora não possamos reduzir a ecoespiritualidade a um único regime religioso, parece que há afinidades entre a ecoespiritualidade e o regime fluído e errante discutido por Leila Amaral (2013).

O interesse pelas "energias cósmicas”, a "gratidão à Mãe Natureza” e a busca pela "Paz interior" testemunham também a condição, aqui neste mundo, da ecoespiritualidade, assim como sua afinidade com tendências que geralmente classificamos como Nova Era ou espiritualidades alternativas que gravitam ao redor do "self". Ao invés da busca da salvação da alma no sentido que nos é familiar, procura-se uma nova consciência capaz de transformar o sujeito e alcançar o "eu verdadeiro" aqui e agora. Esse interesse ainda se vincula ao entendimento de que a "nova consciência" produziria estados mentais e comportamentos capazes de proporcionar aos sujeitos algum tipo de bem-estar ou, se levarmos em conta a dimensão mais comunitária, o "bem-viver". Novos hábitos alimentares, retiros na natureza, meditação ao ar livre, ingestão de beberagens específicas oriundas das sabedorias populares etc. são iniciativas terapêuticas que procuram harmonizar o interior dos sujeitos, desacelerar suas vidas e lhes provocar bem-estar cotidiano a partir de fontes "naturais", livres de toda sorte de artificialidade e riscos atribuída aos modos de vida modernos.

Uma pergunta sociológica importante diz respeito à institucionalidade e aos regimes de pertencimento religioso. Por se tratar de um fenômeno amplo e difuso, não é possível apontar uma única configuração como padrão de organização grupal. É possível encontrar, por exemplo, ecoespiritualidades em instituições do tipo igreja, como é o caso do catolicismo sob influência da Laudati Si e em grupos que praticam retiros religiosos, mas também em grupos cuja dinâmica religiosa é do tipo rede ao invés do tipo instituição de pertencimento - essa é uma das características frequentemente associada à Nova Era (Barker, 1989). Diferentes tipos de organização certamente produzem ecoespiritualidades diferentes; algumas mais abertas e errantes, outras mais ortodoxas e fixas. A despeito disso, parece-nos que a ecoespiritualidade, a mais fluída, ainda prescinde de um conjunto de saberes que são produzidos, preservados e transmitidos por instâncias que redefinem nosso entendimento sobre instituições religiosas. ONGs, 
ecovilas, centros de terapias holísticas, editoras, blogs etc. são instâncias articuladoras das redes ecoespirituais; elas são responsáveis pelo estabelecimento e transmissão de conhecimentos sistemáticos semelhantes às instituiçóes religiosas com as quais estamos familiarizados.

Compreendemos que ecoespiritualidade é um empreendimento de reimaginação religiosa. Tradições diversas e longevas, que passam a circular no interior do que José Jorge de Carvalho (1994, p. 78) chamou de "circuito transnacional de bens de salvação", são apropriadas e traduzidas e amiúde bricoladas pelos agentes e grupos religiosos preocupados em responder às interpelaçóes e demandas de seu tempo. Por esse motivo, elementos religiosos "pagãos", aborígenes e orientais, coabitam espaços e sensibilidades religiosas ecoespirituais e são representados enquanto vias para o advento da nova consciência ambiental. A reimaginação idealiza o passado religioso de determinadas tradiçóes no que toca ao tratamento dispensado à natureza. Essa questáo merece algumas consideraçóes mais amplas, que não são possíveis aqui. Cabe-nos ressaltar que temos em mente as impressóes de mundo "orientalistas" e equivalentes que idealizam, isto é, suprimem a historicidade/diversidade das práticas religiosas do sudeste asiático e outras partes do mundo no que toca ao cuidado com o meio-ambiente. Ao apontarmos essa idealização, não negamos que outros povos de épocas e lugares distintos tinham relaçôes e concepçóes diferentes do que chamamos natureza, mas pontuamos nosso interesse na compreensão das construçôes religiosas de mundo que precisam reimaginar seus mitos ou os mitos de outros povos.

\section{Consideraçóes finais}

Ao pensarmos a relação entre religiáo e ecologia na contemporaneidade, é impossível desemaranhar os que as pessoas pensavam sobre as plantas e os animais daquilo que elas pensam sobre si mesmas. Quando pensamos nessa relação, parece-nos impossível desemaranhar aquilo que as religióes - e os religiosos - pensam da natureza da realização espiritual que aspiram. As representaçóes do meio-ambiente, no que toca à sua diversidade e à integraçáo dos seres humanos nela, como partes da Grande Máe nutridora, sugerem que as religiōes e os religiosos que trilham a vereda ecoespiritual, ou pelo menos parte deles, percebem seus itinerários de fé enquanto caminhada em favor de uma consciência ecológica que estabelece que todos os entes da natureza partilham uma condição numinosa comum e que todos eles são partícipes da jornada sagrada do universo. É assim que as narrativas religiosas da ecoespiritualidade se contrapóem ao ordenamento espaço-temporal linear e quantitativo característico do utilitarismo moderno e ocidental e propóe outra gramática espaço-temporal, baseada na integração da humanidade com os outros seres e entes da natureza.

Muitos dos que enveredam pela ecoespiritualidade entendem que a diversidade da natureza e a diversidade cultural, nela incluída a religiosa, são expressóes da riqueza e do sentido último da vida que contrasta com qualquer racionalidade uniformizadora Boff e Hathaway (2010) chegam a mencionar que a diversidade é o sentido último do próprio universo. As representaçóes que gravitam ao redor da consciência da integração 
entre a humanidade e a natureza evocam o sentido de comunidade e utopia enquanto respostas a anomia da individualizaçáo radical e aos riscos negligenciados pela metanarrativa moderna. Por essas razóes, parece-nos que a ecoespiritualidade está em afinidade com ideias políticas e movimentos identitários e comunitários de nosso tempo, além do movimento ambientalista com quem dialoga.

O desafio que propusemos foi o de descortinar os traços mais marcantes da ecoespiritualidade a partir do entendimento de que estamos diante de um fenômeno produzido pelas interpelaçóes ecológicas lançadas à imaginação religiosa de seres humanos contemporâneos. A reflexividade da modernidade tardia responde aos perigos experimentados por todos nós. Em alguma medida, essa resposta aparece também em forma de religiáo ecologicamente orientada ou, como preferimos, ecoespiritualidade.

Algumas das consideraçóes que levantamos partiram de observaçóes amplas a respeito de iniciativas cotidianas que são orientadas pelo desejo de integração com a natureza e de nosso contato com os estudos das religiosidades contemporâneas ao longo dos últimos anos, além, é claro, do contato com os textos produzidos por autores religiosos que aproximam religião e ecologia. Acreditamos que outros esforços, em especial aqueles de natureza etnográfica, poderão testar algumas consideraçóes que apresentamos nesse estudo e apontar as especificidades de uma tendência religiosa rizomática que está além dos contornos institucionais tradicionais.

\section{Referências}

AMARAL, Leila. Cultura religiosa errante. O que o Censo de 2010 pode nos dizer além dos dados. In: TEIXEIRA, Faustino; MENEZES, Renata. Religióes em Movimento: o Censo de 2010. Petrópolis: Vozes, 2013.

BAPTISTA, Paulo Agostinho Nogueira. Desafios das epistemologias descoloniais e do paradigma ecológico para os estudos de religião. Interações, Belo Horizonte, Brasil, v. 13. n. 23, pp. 94-114, jan./jul.2018.

BARKER, Eileen. New Religious Movements: a practical introduction. Londres: HMSO, 1989.

BECK, Ulrick. Sociedade de risco: rumo a uma outra modernidade. São Paulo: Editora 34, 2011.

BECKFORD, James A. Social Theory and Religion. Nova Iorque: Cambridge University Press, 2008.

BERGER, Peter. Os múltiplos altares da modernidade: rumo a um paradigma da religião numa época pluralista. Petrópolis: Vozes, 2001.

BERRY, Thomas; SWIMME, Brian. The Universe Story: from the primordial flatering forth to the Ecozoic Era. Nova Iorque: Harper One, 1992.

BOFF, Leonardo; HATHAWAY, Mark. O Tao da Libertação: explorando a ecologia da transformação. Petrópolis: Vozes, 2012. 
CARVALHO, José Jorge de. Características do movimento religioso na sociedade contemporânea. Série Antropologia, 114: 01-46, Brasília, Universidade de Brasília, 1994.

CARVALHO, Isabel Cristina Moura; STEIL, Carlos Alberto. A sacralização da natureza e a 'naturalizaçấo' do sagrado: aportes teóricos para a compreensão dos entrecruzamentos entre saúde, ecologia e espiritualidade. Ambient. soc., Campinas, v. 11, n. 2, pp. 289-305, 2008. Disponível em: http://www.scielo.br/scielo. php?script=sci_arttext\&pid=S1414-753X2008000200006\&lng=en\&nrm=iso. Acesso em 28 Maio de 2018.

DWIVEDI. O.P. Hindu religion and Environmental Well-being. In: GOTTLIEB, Roger S. (Org.). The Oxford handbook of Religion and Ecology. Nova Iorque: Oxford University Press, 2010

EATON, Heather. Christianity, ecofeminism and transformation. In: The Wiley Blackwell Companion to Religion and Ecology. Hoboken, Nova Jersey: John Wiley \& Sons Ltd, 2017, pp. 256-271.

ELIADE, Mircea. A Terra, a mulher e a fecundidade. In. ELIADE, Mircea. Tratado de História das Religióes. São Paulo: Martins Fontes, 2008, pp. 193-212.

FAUR, Mirella. O anuário da Grande Máe: guia prático para celebrar a Deusa. São Paulo: Gaia, 2001.

FERNANDES-PINTO, Érika. Sítios Naturais Sagrados do Brasil: inspiraçóes para o Reencantamento das Áreas Protegidas. Tese de Doutorado apresentada ao Programa de Pós-Graduação em Psicossociologia de Comunidades e Ecologia Social - EICOS, Instituto de Psicologia, da Universidade Federal do Rio de Janeiro, como parte dos requisitos à obtençâo do título de Doutora. Rio de Janeiro, 2017, $423 \mathrm{f}$.

GOTTLIEB, Roger S. Introduction: Religion and Ecology - What is the connection and why does it matter? In: GOTTLIEB, Roger S. (Org.). The Oxford handbook of Religion and Ecology. Nova Iorque: Oxford University Press, 2010.

GRENFELL-LEE, Tallessyn Z. Earth as Community Garden: The Bounty, Healing, and Justice of Holy Permaculture. In: HART, John (Org.). The Wiley Blackwell Companion to Religion and Ecology. Hoboken, Nova Jersey: John Wiley \& Sons Ltd, 2017, pp. 410-423.

GROSS, Rita. Goddesses - History of. The Encyclopedia of Religion and Nature. Nova Iorque: Thoemmes Continuum, 2005, pp. 702-705.

HERVIEU-LÉGER, Danièle. O peregrino e o convertido: a religião em movimento. Lisboa: Gradiva, 2008.

HOBGOOD-OSTER, Laura. Ecofeminism - Historic and International Evolution. In: TAYLOR, Bron R. (Org.). The Encyclopedia of Religion and Nature. Nova Iorque: Thoemmes Continuum, 2005, pp. 533-538.

INGOLD, Tim. Ponto, linha, contraponto: do meio ambiente ao espaço fluido. In: 
INGOLD, Tim. Estar vivo. Ensaios sobre movimento, conhecimento e descrição. Petrópolis: Vozes, 2015, pp. 127-143.

IRONS, Edward A. Encyclopedia of Buddhism. Nova Iorque: Facts on File, 2008.

KAZA, Stephanie. The Greening of Buddhism. Promise and Perils. In: GOTTLIEB, Roger S. (Org.). The Oxford handbook of Religion and Ecology. Nova Iorque: Oxford University Press, 2010.

KAZA, Stephanie. Buddhism, Feminism, and the Environmental Crisis: Acting with Compassion. In: ADAMS, Carol (Org.). Ecofeminism and the Sacred. Seattle: Continuum Press, 1993.

KUMAR, Satish. Soil, Soul and Society: a new Trinity for our society. Lews, Reino Unido: Leaping Hare Press, 2013.

LOVELOCK, James. Gaia: a new look at life on Earth. Nova Iorque: Oxford, 2000.

LUCKMANN, Thomas. A religião invisível. São Paulo: Olhos D’água; Loyola, 2014

MAÇANEIRO, Marcial. Religião e Ecologia: cosmovisões, valores, tarefas. São Paulo: Paulinas, 2011.

MCGINNIS, Michael V. Biorregionalism. In: In: TAYLOR, Bron R. (Org.). The Encyclopedia of Religion and Nature. Nova Iorque: Thoemmes Continuum, 2005.

NAES, Arne. The deep ecological movement: some philosophical aspects. In: SESSIONS, George (Org.). Deep Ecology for the Twenty-First Century. Boston: Shambala, 1995.

NASH, James. Christianity. In: TAYLOR, Bron R. (Org.). The Encyclopedia of Religion and Nature. Nova Iorque: Thoemmes Continuum, 2005.

PARTRIDGE, Christopher. The Re-Enchantment of the West: alternative spiritualities, sacralization, popular culture and occulture. Nova Iorque: T\&T Clarke International, 2005. 2V.

PEPPER, David. Modern Environmentalism: an introduction. Londres: Routledge, 2003.

ROBERTSON, Roland. Globalização: teoria social e cultura global. Petrópolis: Vozes, 2000.

SANTOS, Milton. Por uma outra globalização: do pensamento único à consciência universal. Rio de Janeiro: Record, 2001.

SBARDELOTTO, Moisés. Ser por meio dos outros: o ubuntu como cuidado e partilha. IHU-online, São Leopoldo, 6 dez. 2010. Disponível em: <http://www. ihuonline.unisinos.br/artigo/3687-dirk-louw>. Acesso em: 12 out. 2018.

SLOTERDIJK, Peter. Palácio de Cristal. Para uma teoria filosófica da globalização. Lisboa: Relógio D’Água Editores, 2008. 
THOMAS, Keith. O homem e o mundo natural: mudanças de atitude em relação às plantas e aos animais (1500-1800). São Paulo: Companhia das Letras, 2010.

TUCKER, Mary Evelyn; GRIM, John. Ecology and religion. Washington: Island Press, 2014.

ZAFFARONI, Eugênio R. La Pachamama y el humano. Buenos Aires: Ediciones Madres de Plaza de Mayo, 2011.

Recebido: 15 de abril de 2019.

Aprovado: 11 de novembro de 2019. 